\title{
Health Budget Allocation and Performance; and the Budget's Preparedness for Health Events such as COVID-19: Enugu State Perspective
}

\author{
Simon Nnamdi Eneh \\ Ph.D. in Public Health, Texila American University, Nigeria
}

\begin{abstract}
This is an exploratory study of the health budget allocation and performance of a State against the background of its health indices and preparedness for any public health emergency such as COVID19. This is aimed to guide future health programming in the state. Three research instruments (Questionnaire, data collection, and interview guides) were used to collect data, key informant interviews with health planners and managers; synthesis of relevant literature reviews to identify relevant documents; and responses gathered from the public and civil servants. The findings identified eight (8) Ministries, Departments, and Agencies (MDA) under the State Ministry of Health, which is the policy-making body that monitors and coordinates/regulates all health activities in the State. The government budget, donor partners, out-of-pocket expenditures, and contributory schemes are sources of funds for Health. The State's budgetary allocations for health shows an annual increment from reaching 15\% in 2016 to $16 \%$ in 2017 and over 17\% in 2018, surpassing the Abuja Declaration target of $15 \%$ of the state budget. In nominal terms, allocation to the health sector fluctuated between 2011 and 2016 and finally went down in 2018. There is no clearly cut-out budgetary provision for emergency preparedness for health events in the State's health budget. The government has proactively made budgetary provisions for the challenges facing the health care system to facilitate efforts towards addressing them. However, it remains to be seen whether the poor health indices will get better in the long run.
\end{abstract}

Keywords: Budget allocation, Emergency preparedness, Health economics, Health expenditure, Health financing, Health indices.

\section{Introduction}

Health budgets are the principal mechanism by which governments take decisions on health activities. According to [1], total health spending is growing faster than gross domestic product, increasing more rapidly in low- and middle-income countries (Close to $6 \%$ on average) than in high-income countries (4\%), noting that public spending on health is central to universal health coverage, but there is no clear trend of increased government priority for health. A huge portion of the resources consumed by the health sector are stationary e.g., investment in physical infrastructure and human resources, or largely preset e.g., salaries. The room for the operation of decision-makers is narrower than commonly thought. Thus, the internal structure of health expenditure is as important as its total cost. Considering health expenditure entails the analysis of the health sector in all its components. There is a huge mismatch between a country's health financing needs and their current health expenditure [1]. According to [2], developing countries constitute 84 percent of the world population and 90 percent of the universal disease burden, but only 12 percent of global health 
expenditure. The poorest countries bear an even higher portion of the burden of disease and injury, yet they have the least resources for financing health services [1].

Health is financed by public and private funds, and how the budgets are formed, allocated, and used in the health sector is at the center of the agenda for Universal Health Coverage [3]. Budget outcomes can be measured in terms of the aggregate level of spending, the composition of the spending, and the efficiency of spending. According to [4], public budgets are the instruments through which governments allocate the country's financial resources, including but not limited to financing health services. Even in the most open and democratic countries, a robust and transparent budget system can be difficult to achieve [4], emphasizing that supporting governments to strive towards achieving an open budget and improving the budget system can be a good starting point for any country's health budget advocacy. Bringing about changes in policy and budget allocations are often long-term objectives, and there will be many points during the budgetary process where one can make a change that will bring influence to bear and help re-shape the policy environment. It's important that one measures these benchmarks against the desired budget outcome so that one is able to monitor and evaluate what activities are being achieved.

Budget outcomes can be measured in terms of the aggregate level of spending, the composition of the spending, and the efficiency of spending.

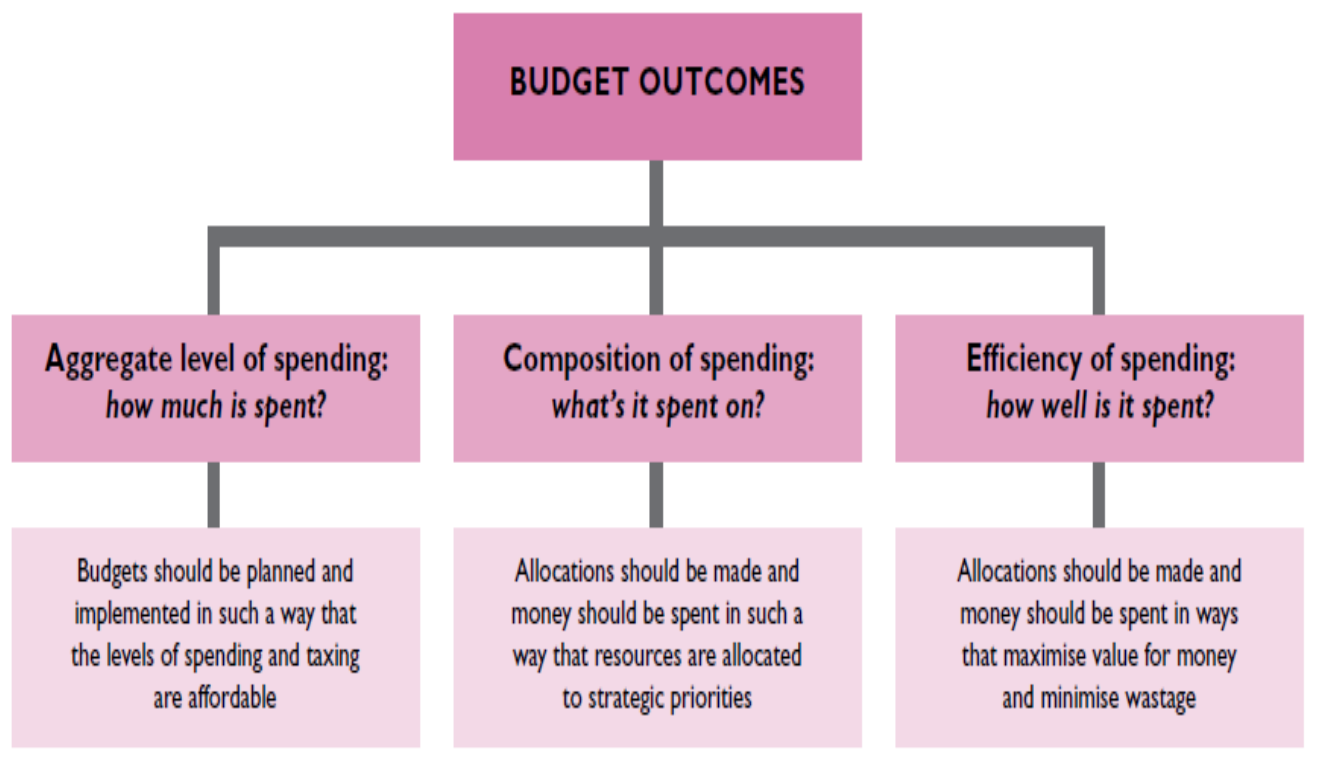

Figure 1. Budget outcomes: Level, Composition and Efficiency of Spending

Source: Save the Children, 2012

These various measures of levels, composition, and efficiency of spending are aligned respectively with different objectives as follows:

1. Budgets must be planned and implemented in a way that the levels of spending and taxing are affordable.

2. Allocations should be made, and money spent in such a way that resources are allocated to strategic priorities.
3. Allocations should be made, and money spent in ways that maximize value for money and minimize wastages.

The way a budget is formulated and allocated, especially at sub-national levels of government, has a direct impact on how well and how efficiently funds can and will be used. A fair distribution of resources across populations and/or geographical areas is likely to have a direct impact on health sector outputs 
[5]. Similarly, how health managers will be able to spend their money largely depends on what the budget allocation is [3]. Not only is the budget envelope amount relevant, but so too is how that total amount is structured, how it flows into the system, timing of disbursements, and how it will enable health financing to function in practice and to purchase the needed health services [3]. According to [6] in health, countries face challenges at all stages of the PFM cycle, including how to align budget allocations with sector needs, how to ensure effective disbursement, and how to make the budget system more accountable and transparent. These set of challenges also applies to States within the countries.

In Nigeria, money allocated to the health sector is amongst the bottommost. The Abuja declaration stipulates that $15 \%$ of the Budget is to be allocated to the health sector; however, that has not been achieved in most States and in the Nation [7]. If Nigeria hopes to reverse the trend of decline and realign its economy for allencompassing growth, then Nigeria will need to meaningfully upgrade its health sector budget. Furthermore, according to [8], Enugu State has poor health indices which are higher than the national average in terms of high maternal mortality (1400 per 100,000 live births; National 814 per 100,000 live births) and child mortality (40.6/1000 live births), moderate fertility, high literacy levels and above-average use of modern contraceptives. Bringing about changes in policy and budget allocations are often long-term objectives, and there will be many points during the budgetary process where one can make a change that will bring influence to bear and help re-shape the policy environment.

Specifically, this study looked at the following objectives:

1. To find out the health programs, projects and events funded in Enugu State between 2011 and 2017.
2. To ascertain how allocations of the health sector Budget are determined between 2011 and 2017.

3. To determine how the funds are released between 2011 and 2017.

4. To determine the provisions if any, made for emergency health events such as COVID-19.

Budget advocacy challenges the notion that public budgets are exclusively the business of government [4]. Regularly tracking disbursements (when funds are released) at particular points in the system and making comparisons with the budget allocations and schedule of disbursements, can indicate whether the funds are released regularly and spent as planned or if there are leakages. 'Leakages' refers to resources that are being disbursed but not spent as intended or resources that were disbursed but were not received and cannot be traced. As noted earlier, where there are capacity constraints, funds received may not always be spent in full and may be returned. The initial health budget's main concern might also change, which may require resources to be diverted during the budget period, which one should be able to track.

Comparing allocation and disbursement patterns over time can help stakeholders identify trends, which is particularly valuable when advocating for the various levels of government to fulfill any commitments made. Assessing the trends can reveal quickly how the government is progressing towards a specific target such as the Abuja target of allocating $15 \%$ of the budget to health.

According to $[9,10], 2019$ Open Budget Survey reported that COVID-19 hit when growing inequality and weakening democracy moved people across the globe to call into question their governments' handling of public resources - a key theme of the 2019 Open Budget Survey report. The sheer scale of the interventions needed to confront the health and economic consequences of the COVID-19 pandemic has challenged governments' 
capacity to manage resources effectively and equitably in unprecedented ways $[9,10]$. In a research conducted to assess open governance practices on fiscal emergency packages by International Budget Partnerships and her local research partners in 120 countries, it was reported [9] that the main finding is that governments are falling short of managing their fiscal policy response to the crisis in a transparent and accountable manner as shown below.

Table 1. Levels of Accountability in Early Covid Fiscal Policy Response

\begin{tabular}{|c|c|c|}
\hline Level of accountability & No of countries (out of 120) & Countries \\
\hline Substantive & 0 & - \\
\hline Adequate & 4 & Australia, Norway, Peru, Philippines \\
\hline Some & 29 & $\begin{array}{l}\text { Bangaledesh, Brazil, Bulgaria, Canada, } \\
\text { Chile, Colombia, Costa Rica, Croatia, } \\
\text { Fiji, France, Germany, Indonesia, Italy, } \\
\text { Jamaica, Japan, Kyrgyz Republic, } \\
\text { Mongolia, New Zealand, Nigeria, } \\
\text { Paragauy, Poland, Portugal, Sierra } \\
\text { Leone, Slovakia, South Africa, Sweden, } \\
\text { United Kingdom, United States }\end{array}$ \\
\hline Limited & 55 & $\begin{array}{l}\text { Afghanistan, Angola, Argentina, } \\
\text { Armenia, Azerbaijan, Bolivia, Bosnia } \\
\text { and Herzegovina, Botswana, Cameroon, } \\
\text { China, Cote d'Ivoire, Czech Guatemala, } \\
\text { Honduras, Jordan, Kazakhstan, Kenya, } \\
\text { Lesotho, Liberia, Macedonia, } \\
\text { Madagascar, Malaysia, Mali, Mexico, } \\
\text { Moldova, Mozambique, Namibia, } \\
\text { Nepal, Nicaragua, Niger, Pakistan, } \\
\text { Papau New Guinea, Romania, Russia, } \\
\text { Rwanda, Senegal. Serbia, Somalia, } \\
\text { South Korea, Spain, Sri Lanka, Sao } \\
\text { Tome e Principe, Thailand, Timor- } \\
\text { Leste, Togo, Trinidad and Tobago, } \\
\text { Uganda, Ukraine, Vietnam, Zambia }\end{array}$ \\
\hline Minimal & 32 & $\begin{array}{l}\text { Albania, Algeria, Benin, Burkina Faso, } \\
\text { Burundi, Cambodia, Chad, Comoros, } \\
\text { Dem Rep of Congo, Egypt, Equatorial } \\
\text { Guinea, Eswatini, Ethiopia, Hungary, } \\
\text { India, Iraq, Lebanon, Malawi, Morocco, } \\
\text { Myanmar, Qatar, Saudi Arabia, South } \\
\text { Sudan, Sudan, Tajikistan, Tanzania, The } \\
\text { Gambia, Tunisia, Turkey, Venezuela, } \\
\text { Yemen, Zimbabwe }\end{array}$ \\
\hline
\end{tabular}

Source: IBP, (May 2021): p.3

More than two-thirds of the governments that were looked at, across many regions and income levels, have only provided limited or minimal levels of accountability in the 
introduction and implementation of their early fiscal policy responses $[9,11]$. In about half of the countries in the assessment, COVID-19 response packages took the form of supplementary budget laws (or other types of laws) approved by parliaments (even if in haste), guaranteeing some level of debate and accountability [9].

Countries that decided to have legislatures debate and approve their COVID-19 response packages did better in terms of both transparency and oversight [9, 12], emphasizing that even in times of crisis, it is possible to follow due process and maintain basic functional accountability processes. Decisionmaking around COVID response packages and their implementation includes very little or no input from the public. Citizen participation in the formulation and execution of COVID-19 policy responses was virtually non-existent, excluding the public from having a voice in decisions on priority-setting during the pandemic and depriving governments of contributions that could greatly improve the effectiveness of their actions [9]. Consequently, the government should take the opportunity provided by the COVID-19 health event to plan and implement their policy responses in a more open and collaborative way, emphasizing keeping citizens informed and promoting more effective and equitable outcomes [9].

The findings from this study are of significant benefit to individuals (Singly and in groups), the government, and the research world. The results will assist government and health administrators in health policy formulation, administration, and implementation for better service delivery. This study provides a baseline reference source for many researchers and the needed data that would assist the Enugu State Government, Health sectors, and other stakeholders in designing strategies and goals that will improve Universal Health Coverage. The findings of this study provide the basis for more realistic estimates of resources required in the State's health sector. Most importantly, it is believed that the findings from this study may stimulate further research and investment, which will ultimately improve the budget allocations to the Enugu state Health sector.

It is worthy of note that the analyses were based on documents available, with a few clarifications called for where needed. Moreover, the staff members' responses showed a bit of reluctance to offer the needed explanations, which made eliciting vital information and data quite challenging. Some government officials were uncooperative in terms of releasing documents on government finances, and the reason for such reluctance could not be elicited from some of them. As such, the study took more time and effort than estimated because the researcher spent more days to explain the need for the study since it is very important to gain the support of the public to collect and share information and data.

\section{Methods and Materials}

Three sets of instruments (One questionnaire, a data collection guide, and an interview guide) were employed to collect both quantitative and qualitative data. Data were collected from a sample of 40 relevant authorities (20 Public servants and 20 Civil servants) of the Ministries of Health and Finance in Enugu state and 160 respondents from the public.

The questionnaire was used for the public, the interview guide for the public servant and civil servants in both Ministries of Health and Finance, and the data collection guide used for desk review of available and relevant documents. All the respondents were further given an opportunity to provide information and suggestions on what they think would be helpful to enable improvement in health care budgeting in the State. The respondents' eligibility to participate included being residents in Enugu for at least 15 years, between 15 and 64 years of age, and 
willingness to participate. The overall response rate was $97.5 \%$.

Using the data collection guide, systematic reviews of official documents relating to budget allocations and releases for the period under review (2011 to 2017) was conducted in the Ministries of Health and Finance. The desk reviews of documents yielded quantitative data regarding budget allocations and performance status. These reviews allowed for analysis of the financial documents from various sources from 2011 to 2017. As such, the guide had sections that surveyed the following:

1. Health programs, projects and events funded in Enugu State between 2011 and 2017.

2. Key Projects with budgetary emphasis in Health Sector of Enugu state.

3. The proportion of Annual budget (2011 to 2017) that went to the Health Sector.

4. Enugu state health budget releases.

\section{Results}

\section{The organizational Structure of Enugu state}

The findings of the study showed that as the time of data collection, the Health Sector in Enugu State comprises eight (8) Ministries, Departments, and Agencies (MDA) under the leadership of the State Commissioner for the State Ministry of Health. The Enugu State Ministry of Health is the policy-making body cum monitors, and coordinates/regulates all Health activities in the State. Each of these is established by law and is granted a certain degree of autonomy. Other MDAs in the health sector are:

1. State Hospitals Management Board (SHMB) is responsible for all secondary Health outfits in the State.

2. The State Primary Health Care Development Agency (ENSPHCDA) is responsible for all the over 1000 primary Health Care (PHC) facilities in the State.

3. The State Drugs and Medical Consumables Management Agency (ENSDMMA) lumbered with the responsibility of logistics, supply, and distribution of medicine and medical consumables amongst all Health Facilities in the State.

4. The Specialist Hospital Board (SHB) function as a state-owned tertiary health facility.

5. The College of Nursing and Midwifery (CNM); is responsible for the training of the Human resources required by the State.

6. The College of Health Technology (CHT); responsible for the training of lower cadre of Human resource for Health.

7. The Enugu state health insurance agency.

8. The Enugu State Health Trust Fund; expected to be the source of funds for the health sector. The fund shall be generated from $5 \%$ of state internally Generated Revenue (IGR) and $1 \%$ of the statutory allocation of each of the local government councils of the state.

Each of these MDAs is autonomous in maintaining and implementing its budgetary provision as far as recurrent expenditure is concerned. However, capital funds are accessed through the Honorable Commissioner for Health's consent who endorses relevant memos to His Excellency the Executive Governor of the State for approval.

\section{The health Indices in the State}

The State health indices from the MICS survey in 2016 and 2017 and the NDHS 2018 showed significant disparity from the National Average as depicted in the table below: 


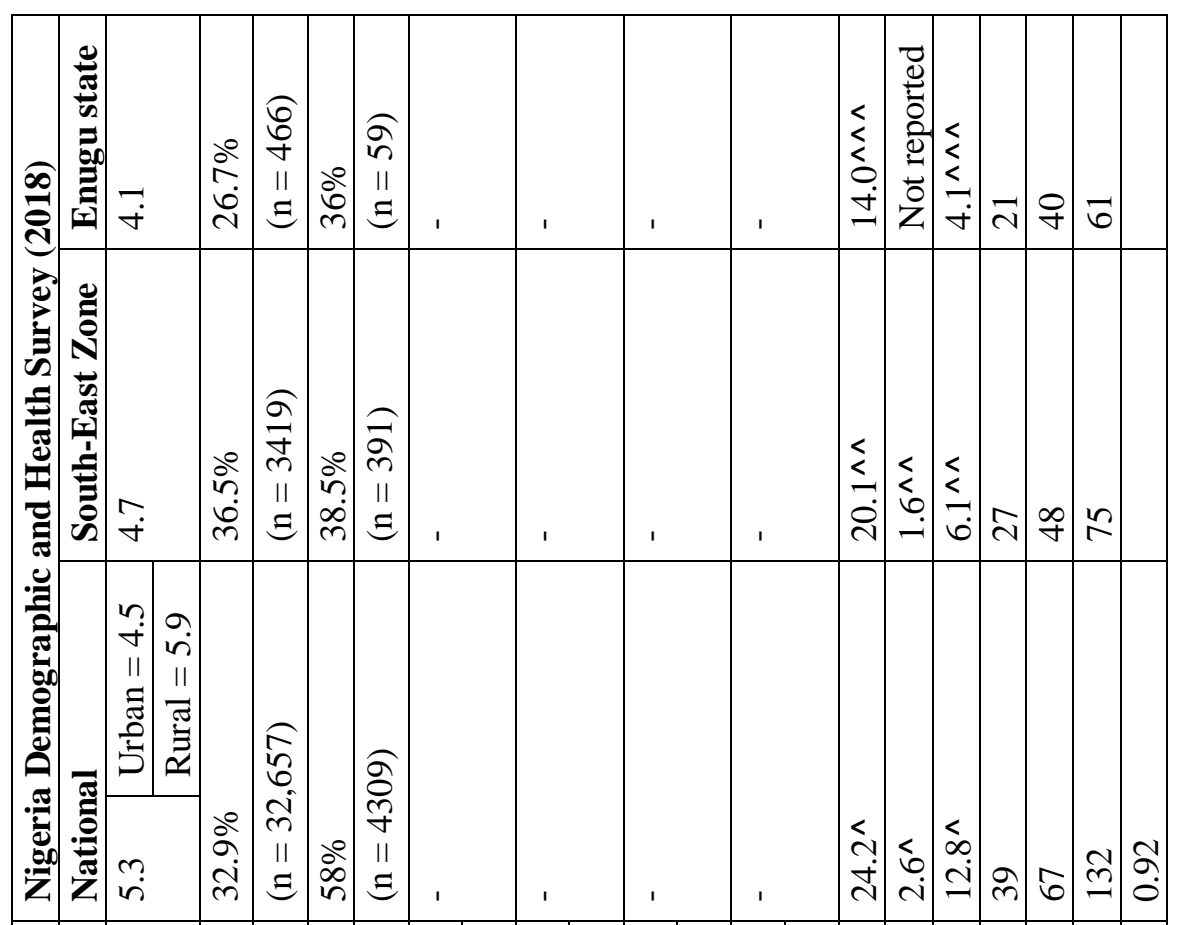

제

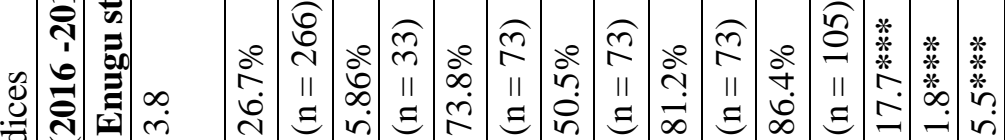
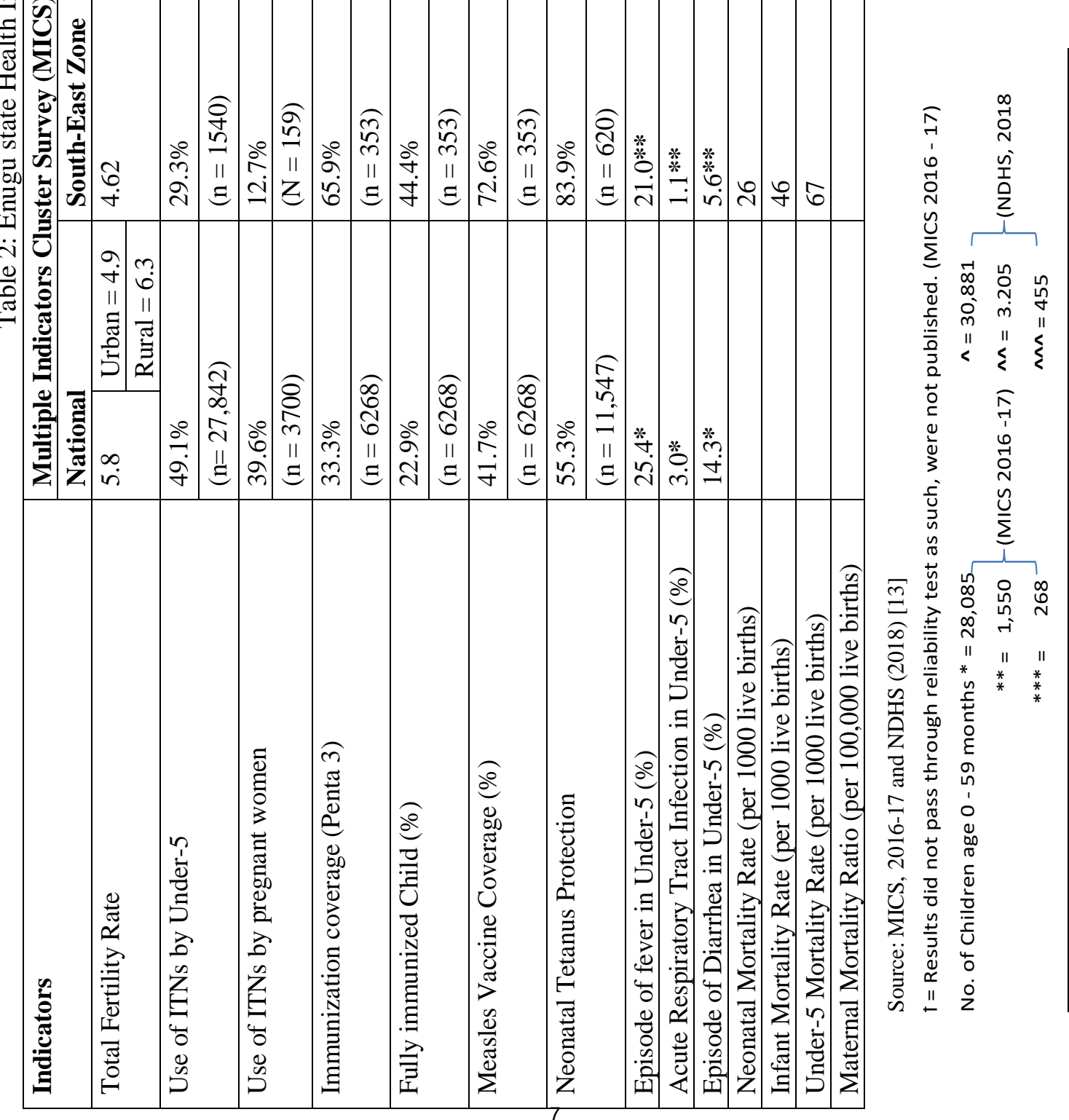


\section{The Sources of Funds for Health Programs, Projects and Events}

In general, sources of funds for Health in Enugu State were identified as:

1. Government budget (from Federal and State sources).

2. Donor partners - Through various health projects and initiatives.

3. Out of pocket expenditures from patients and relatives.

4. Contributory schemes (NHIS and few CBHIS Pilots).

However, the exact percentage of the total health budget for each Health program could not be clearly defined because inputs that impact on programs like maternal health, child health, and reproductive health cut across a number of capital and recurrent line items in the budget of various agencies within the sector.

\section{The Allocations of the Health Sector Budget}

Enugu State Government has made some giant strides recently; from 2006 to 2018, budgetary allocations for health constituted an average of $12 \%$ of the State's annual budget, with allocation reaching the Abuja Declaration target of $15 \%$ in 2016 and increasing further to $16 \%$ in 2017 and over $17 \%$ in 2018. Respondents consider the allocations and appropriation of health budget as adequate for 2017 and 2018, considering that the state has surpassed the Abuja declaration of $15 \%$ of state budget to the health sector.

In nominal terms, allocation to health sector decreased from $\$ 6$.8billion in 2011 to \$8.4billion in 2014 and reversed to 4.8 billion and rising to $\$ 6.4$ billion in 2016, in 2018, it went down $\$ 3.2$ billion.

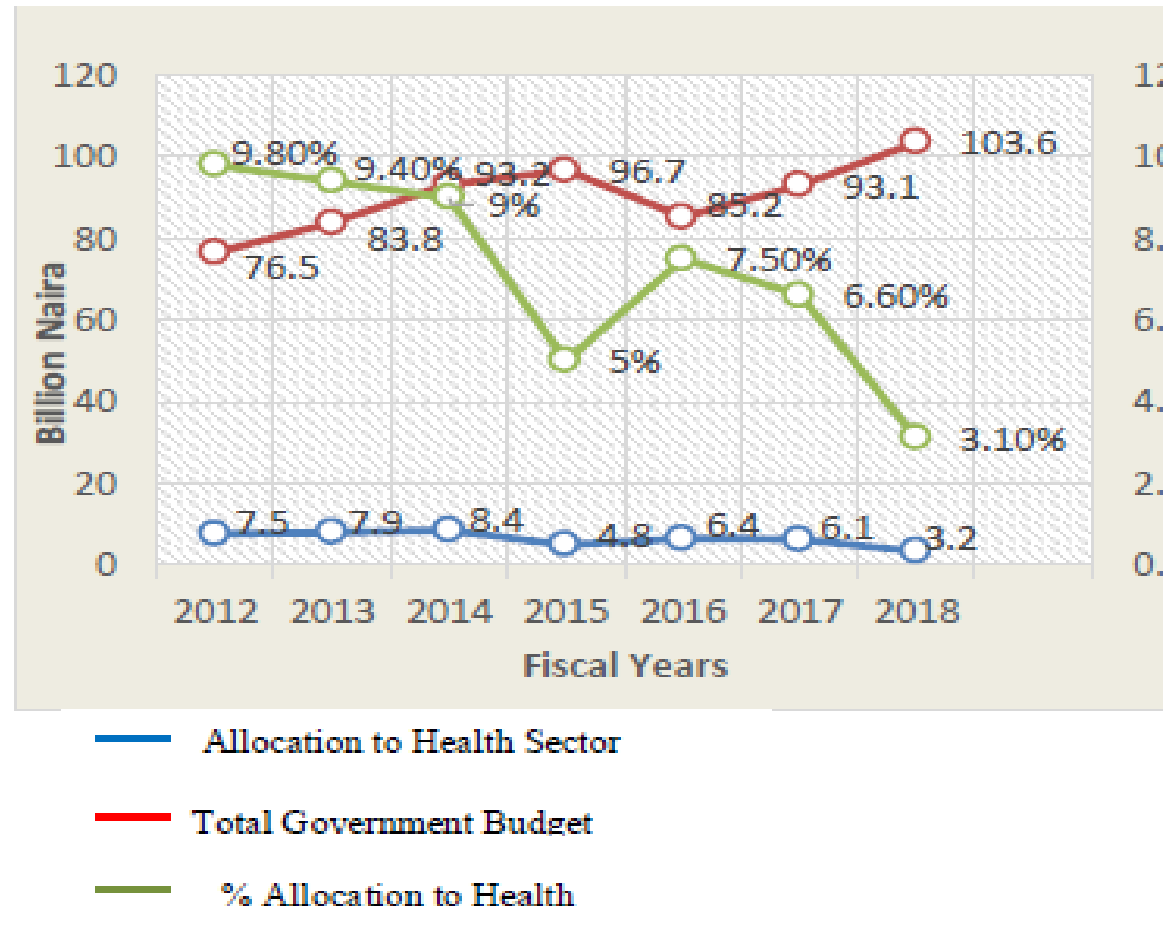

Figure 2. Enugu state Budget Allocation to Health 
Table 3: Enugu state Government Budget Allocation to Health

\begin{tabular}{|l|l|l|l|l|l|l|l|l|}
\hline Fiscal year & 2011 & 2012 & 2013 & $\begin{array}{l}201 \\
4\end{array}$ & 2015 & 2016 & 2017 & 2018 \\
\hline $\begin{array}{l}\text { Health budget allocation } \\
\text { (billion naira) }\end{array}$ & 6.8 & 7.5 & 7.9 & 8.4 & 4.8 & 6.4 & 6.1 & 3.2 \\
\hline $\begin{array}{l}\text { Total Government budget } \\
(\%)\end{array}$ & 66.4 & 76.5 & 83.8 & 93.2 & 96.7 & 85.2 & 93.1 & 103.6 \\
\hline $\begin{array}{l}\text { Government budget } \\
\text { allocation to health (\%) }\end{array}$ & 10.2 & 9.8 & 9.4 & 9.0 & 5.0 & 7.5 & 6.6 & 3.1 \\
\hline
\end{tabular}

Source: Enugu state Ministry of Finance (2019) [14]

From the above table, the allocation to health did not get to the $15 \%$ recommended by WHO. Furthermore, in spite of the meager amount of money allocated to health. The amount eventually released is reasonably high.

\section{The Release of Funds for Health}

Table 4. Enugu State Health Budget Releases

\begin{tabular}{|l|l|l|l|l|}
\hline Year & $\begin{array}{l}\text { Total state budget } \\
\text { (billion naira) }\end{array}$ & $\begin{array}{l}\text { Health budget } \\
\text { (billion naira) }\end{array}$ & $\begin{array}{l}\text { \% Of budget } \\
\text { allocation to health }\end{array}$ & $\begin{array}{l}\text { Actual releases and } \\
\text { percentage (billion naira) }\end{array}$ \\
\hline 2011 & 66.4 & 6.8 & 10.2 & $4.4[64.7 \%]$ \\
\hline 2012 & 76.5 & 7.5 & 9.8 & $4.1[54.7 \%]$ \\
\hline 2013 & 83.8 & 7.9 & 9.4 & $5.8[73.4 \%]$ \\
\hline 2014 & 93.2 & 8.4 & 9.0 & $5.6[66.7 \%]$ \\
\hline 2015 & 96.7 & 4.8 & 5.0 & $4.2[87.5 \% 1$ \\
\hline 2016 & 85.2 & 6.4 & 7.5 & $5.8[90.6 \%]$ \\
\hline 2017 & 93.1 & 6.1 & 6.6 & $5.5[90.2 \%]$ \\
\hline
\end{tabular}

Source: Enugu state Ministry of Finance (2019) [14]

From the Table above, the actual releases from the budget allocation showed increases from 2011 through 2017, except for slight fluctuations.

\section{Preparedness for Emergency Health Events such as Covid-19}

Regarding emergency preparedness for health events such as COVID-19, the findings showed that there is no such budgetary provision in the health budget through the years studied.

\section{Discussion}

\section{The Organizational Structure of Enugu State}

The Health Sector comprises of the following health institutions to work collaboratively to strive towards optimum health outcomes for the residents of the State.

1. State Hospitals Management Board (SHMB) is responsible for all secondary Health outfits in the State.

2. The State Primary Health Care Development Agency (ENSPHCDA) is responsible for all the over 1000 primary Health Care (PHC) facilities in the State.

3. The State Drugs and Medical Consumables Management Agency (ENSDMMA) is lumbered with the responsibility of logistics, supply, and distribution of medicine and medical consumables amongst all Health Facilities in the State.

4. The Specialist Hospital Board (SHB) functions as a state-owned tertiary health facility. 
5. The College of Nursing and Midwifery $(\mathrm{CNM})$; is responsible for the training of the Human resources required by the State.

6. The College of Health Technology (CHT); responsible for the training of lower cadre of Human resource for Health.

7. The Enugu State Ministry of Health is the policy-making body cum monitors, and coordinates/regulates all Health activities in the State. Each of these MDAs is autonomous in maintaining and implementing its budgetary provision as far as recurrent expenditure is concerned. However, capital funds are accessed through the Honorable Commissioner for Health's consent, who endorses relevant memos to His Excellency the Executive Governor of the State for approval. New agencies were created in 2018 by signing of law for their establishment, and these agencies are.

8. The Enugu state health insurance agency.

9. The Enugu State Health Trust Fund; expected to be the source of funds for the health sector. The fund shall be generated from 5\% of state internally Generated Revenue (IGR) and $1 \%$ of the statutory allocation of each of the local government councils of the state.

The state health system operation is predicated on the existing policy of the federal government thus, tertiary health care is the responsibility of the federal government, the secondary and primary health care are those of the State and the Local Governments, respectively. However, the two sub-national tiers of government collaborate and complement each other with the aim of meeting the health needs of the people in the State.

The State Ministry of Health directs, monitors, and supervises all health services in the state, and is saddled with the responsibility of health manpower development and organization and implementation of secondary health care. The State agency -- State Primary Health Care Development Agency oversees the
Primary Healthcare facilities under the policy of Primary Health Care Under One Roof (PHCUOR), and in collaboration with the local governments, supervises the primary health care and diseases control. The Local Government in conjunction with the ENSPHCDA, organizes and implements primary health care activities at the community level and is also responsible for funding and coordinating services delivery at the grassroots level.

\section{The health Indices in the State}

It is noteworthy that the health indices in the State fluctuate over time when compared with the Nation and the Zonal data. Moreover, it may not be surprising that the health indices in the State remained somewhat static without improvement between reports as published by 2017 MICS [13] and that of the 2018 NDHS [8].

According to [15], some studies conducted in African countries have demonstrated an association between medical outcome and healthcare expenditures and a statistically significant relationship between health expenditures and health outcomes. Although this study was not set up to explore this relationship, it can be seen that the health indices in the State were static over the years despite an upward trend in budget allocations which were not matched with expenditures.

\section{The Sources of Funds for Health Programs, Projects, and Events}

The main source and highest contribution of funding is from the government budget. It is of note that the government has prioritized health over other institutions, and health budget has been the second-highest in the state over a decade.

Development assistance in Enugu state contributes close to $14 \%$ of the budget on health, while the state internally generated revenue constitutes just about $11 \%$ of the total budget [14]. The Enugu State Health Trust 
Fund is to be generated from $5 \%$ of State IGR and $1 \%$ of the statutory allocation of each of the local government councils of the state, also expected to be functional in 2018 is still in the teething stage.

The exact percentage of the total health budget for each health program could not be clearly defined because inputs that impact on programs like maternal health, child health, reproductive Health cut across a number of capital and recurrent line items in the budget of various agencies within the sector. As an example, the Elimination of Mother to Child Transmission of HIV services which is a component of reproductive, Maternal, Neonatal, and Child Health, is captured as a budget line for the Enugu State Agency for Control of Aids, TB, and Malaria. In addition, capital expenditure such as refurbishing facilities or the purchase of equipment that contribute to improved delivery of $\mathrm{RMNCH}$ services has a broad impact on the entire health system. However, certain programs have been given prominence and are captured separately in the state Budget. These programs include Routine Immunization, Nutrition and Child spacing (Family Planning).

\section{The Allocations of the Health Sector Budget}

The State adopted the medium-term Expenditure Framework (MTEF), which is in line with the State Fiscal Responsibility Amendment Law 2009. This is an integrated approach to budgeting and public financial management for the harmonization of all expenditure programs with available resources. It MTEF forecasts likely available resource over 3years and link the annual spending of MDAs with government long-term strategies as articulated under the various state developmental plans/policies. Using the Medium-term sector as a subset of MTEF envelopes are determined for the health MDAs. Despite the use of the MTSS as a financial and planning tool, responders still think that the health sector Budget preparation is fragmented and uncoordinated. On receipt of Budget call circulars from the Department of Budget Monitoring and Evaluation, the ministry of health only prepares Budget for itself under the department of PRS, and in consultation with relevant stakeholders, same is done independently by other Health MDAs, after which MDA defend their Budget in the House of Assembly. Funds are allocated directly to the respective MDA. It is therefore not uncommon to find duplication of programs/activities in the health sector Budget.

Enugu State Government has made some giant strides recently; from 2006 to 2018, budgetary allocations for health constituted an average of $12 \%$ of the State's annual budget, with allocation reaching the Abuja Declaration target of $15 \%$ in 2016 and increasing further to $16 \%$ in 2017 and over $17 \%$ in 2018 and $20 \%$ in 2019. In addition to progressive budgetary allocations, the health sector also experienced increased participation of Civil Society Organizations and community-based organization in budget planning and monitoring of implementation. Regular meetings between the CSOs, CBOs, and the state and LGA health officials also led to increased efficiency and accountability in the utilization of budgetary funds at the LGA and state levels.

\section{The Release of Funds for Health}

In nominal terms, allocation to the health sector decreased from 2014 and reversed in 2016, and in 2018 it went down. Budgeting allocation for health is meaningless without consideration of budget release and utilization in the sector, which constitute critical factors reviewed by ministries responsible for allocating and disbursing public budgetary resources. Funding approvals are centralized at the level of the Governor. While acting, the Deputy Governor has an approval limit. At the level of the Ministry of Finance and Accountant Generals office, there are many other competing sector demands. 


\section{Preparedness for Emergency Health}

The State health Budget did not provide for emergency situations in health. The COVID-19 pandemic has stimulated thoughts among policy and decision-makers that should drive the budget provisions and budgeting process going forward.

More than two-thirds of the governments that were looked at, across many regions and income levels, have only provided limited or minimal levels of accountability in the introduction and implementation of their early fiscal policy responses $[9,10]$. It is also noted that in about half of the countries in our assessment, COVID-19 response packages took the form of supplementary budget laws (or other types of laws) approved by parliaments (even if in haste) guaranteeing some level of debate and accountability; and that countries that decided to have legislatures debate and approve their COVID-19 response packages did better in terms of both transparency and oversight, emphasizing that even in times of crisis it is possible to follow due process and maintain basic functional accountability processes [9]. It has been reported that decision-making around COVID response packages and their implementation includes very little or no input from the public [9]. It has also been stated that citizen participation in the formulation and execution of COVID-19 policy responses was virtually non-existent [9]. This has resulted in excluding the public from having a voice in decisions on priority-setting during the pandemic and depriving governments of contributions that could greatly improve the effectiveness of their actions [9]. Thus, the government is required to take the opportunity provided by the COVID-19 health event to plan and implement their policy responses in a more open and collaborative way, emphasizing keeping citizens informed and promoting more effective and equitable outcomes [9].

\section{Conclusion}

The Enugu State's poor health indices, which are higher than the national average, and the other challenges facing the health care system, has recently caused the state to increase budgetary allocation to the health sector to facilitate efforts to address the many challenges in that sector. However, it remains to be seen whether the poor health indices will get better in the long run.

The State Ministry of Health needs to constantly and collaboratively work with the State Ministry of Finance to prioritize activities of the health sector and facilitate releases. There is also a need for a more realistic health budget that can be matched by expenditure in other to improve health outcomes. As such, emphasis should be on policies to address the numerous bottlenecks encountered in releases of funds towards health programs. Partners need to provide support to the government towards improving internally generated funds that will enhance sustainability and the development of realistic budget estimates. The need to further understudy the pattern of health budget allocation and performance from 2018 to 2021 cannot be overestimated to inform future decisions.

\section{Conflict of Interest}

None associated with this study.

\section{Acknowledgement}

I am grateful to the Texila America University that gave me the opportunity to study a doctoral degree in public health at this great and renowned institution. Thank you for providing a vigorous learning environment for me and for encouraging creativity, interaction, and participation in academic interactions between the University and her students. I am grateful to the entire faculty, mentors, academic coordinators, and team in the administrative section of this institution. 


\section{References}

[1] Xu K, Soucat A \& Kutzin J et al. (2018). Public Spending on Health: A Closer Look at Global Trends. Geneva: World Health Organization; 2018 (WHO/HIS/HGF/HFWorkingPaper/18.3). Licence: CC BY-NC-SA 3.0 IGO.

[2] Gottret, Pablo; Schieber, George. 2006. Health financing revisited: a practitioner's guide (English). Washington, DC: World Bank. http://documents.worldbank.org/curated/en/8740114 68313782370/Health-financing-revisited-apractitioners-guide.

[3] Rajan, D., Barroy, H, and Stenberg K., (2016). Budgeting for health. In: Schmets G, Rajan D, Kadandale $\mathrm{S}$, editors. Strategizing national health in the 21st century: a handbook. Chapter 8. Geneva: World Health Organization. http://apps.who.int/iris/bitstream/handle/10665/2502 21/9789241549745-chapter8eng.pdf?sequence $=11 \&$ isAllowed $=\mathrm{y}$.

[4] Save the Children, (2012). Health Sector Budget Advocacy: A guide for civil society organisations. https://www.who.int/pmnch/media/news/2012/2012 05_health_sector_budget_advocacy.pdf.

[5] Cashin, C., (2016). Health financing policy: the macroeconomic, fiscal, and public finance context. Washington (DC): World Bank Group. http://documents.worldbank.org/curated/en/3940314 67990348481/Health-financing-policy-themacroeconomic-fiscal-and-public-finance-context.

[6] WHO, (2018). Public Spending on Health: A Closer Look at Global Trends. WHO/HIS/HGF/HFWorkingPaper/18.3.

http://apps.who.int/iris.

[7] Kress Daniel H., Su Yanfang and Wang Hong (2016). Assessment of Primary Health Care System Performance in Nigeria: Using the Primary Health Care Performance Indicator Conceptual Framework. Health Systems \& Reform, 2(4):302-318, 2016 2016 Bill and Melinda Gates Foundation ISSN: 2328-8604 print $/ 2328-8620$ online DOI: 10.1080/23288604.2016.1234861.

[8] Nigeria Demographic and Health Survey (2018). National Population Commission Abuja, Nigeria. The DHS Program ICF Rockville, Maryland, USA October 2019.
[9] International Budget Partnership, (May 2021). Managing COVID funds: The accountability gap. https://internationalbudget.org/covid/.

[10] Organization for Economic Cooperation and Development (10 May 2021). The territorial impact of COVID-19: Managing the crisis and recovery across levels of government https://www.oecd.org/coronavirus/policyresponses/the-territorial-impact-of-covid-19managing-the-crisis-and-recovery-across-levels-ofgovernment-a2c6abaf/.

[11] United Nations (April 2020). Policy Brief: The Impact of COVID-19 on Women https://reliefweb.int/sites/reliefweb.int/files/resource s/policy-brief-the-impact-of-covid-19-on-womenen.pdf.

[12] World Health Organization, (2022). Health Budget: Overview. https://www.who.int/healthtopics/health-budget\#tab=tab_1.

[13] National Bureau of Statistics (NBS) and United Nations Children's Fund (UNICEF). (2017) Multiple Indicator Cluster Survey 2016-17, Survey Findings Report. Abuja, Nigeria: National Bureau of Statistics and United Nations Children's Fund. https://www.unicef.org/nigeria/sites/unicef.org.niger ia/files/2018-09/Nigeria-MICS-2016-17.pdf.

[14]Enugu State Ministry of Budget and Planning (July 2018). Enugu State Health Expenditure Report, 2018. 2018 Second Quarter and Mid-Year Budget Implementation Report.

[15]Bein, Murad, and Coker-Farrell, Elizabeth Y., (Mar 2020). The association between medical spending and health status: A study of selected African countries Malawi Med J.; 32(1): 37-44. doi: $10.4314 / \mathrm{mmj}$. v32i1.8. https://www.ncbi.nlm.nih.gov/pmc/articles/PMC736 $6161 /$. 